OPEN ACCESS

Edited by:

Lluis Tort,

Autonomous University of

Barcelona, Spain

Reviewed by:

Malgorzata Witeska

University of Natural Sciences and

Humanities of Siedlce, Poland

Natalie Christina Steinel,

University of Massachusetts Lowell,

United States

*Correspondence:

Jing-Xia Liu

ichliu@mail.hzau.edu.cn

tThese authors share first authorship

Specialty section:

This article was submitted to

Comparative Immunology,

a section of the journal

Frontiers in Immunology

Received: 11 July 2019

Accepted: 21 October 2019

Published: 08 November 2019

Citation:

Chen M, Luo Y, Xu J, Chang M-X and Liu J-X (2019) Copper Regulates the Susceptibility of Zebrafish Larvae to Inflammatory Stimuli by Controlling

Neutrophil/Macrophage Survival.

Front. Immunol. 10:2599

doi: 10.3389/fimmu.2019.02599

\section{Copper Regulates the Susceptibility of Zebrafish Larvae to Inflammatory Stimuli by Controlling Neutrophil/Macrophage Survival}

\author{
MingYue Chen ${ }^{1 \dagger}$, Yi Luo ${ }^{1 \dagger}$, JiangPing Xu ${ }^{1 \dagger}$, Ming-Xian Chang ${ }^{2}$ and Jing-Xia Liu ${ }^{1 *}$ \\ ${ }^{1}$ Key Laboratory of Freshwater Animal Breeding, Ministry of Agriculture, College of Fisheries, Huazhong Agricultural \\ University, Wuhan, China, ${ }^{2}$ State Key Laboratory of Freshwater Ecology and Biotechnology, Institute of Hydrobiology, \\ Chinese Academy of Sciences, Wuhan, China
}

Copper has been revealed to negatively affect the hematopoietic system, which has an important function in immune pathogen defense, but little is known about the potential mechanism. In this study, copper-stressed larvae exhibited significantly increased mortality as well as reduced percentages of GFP-labeled macrophages and neutrophils after Aeromonas hydrophila (A. hydrophila) infection. However, those copper-stressed GFP-labeled macrophages and neutrophils showed more rapid responses to $A$. hydrophila infection. The transcriptional profiles in copper-stressed macrophages or neutrophils were unveiled by RNA-Sequencing, and KEGG pathway analysis revealed enrichment of differentially expressed genes (DEGs) in lysosome, apoptosis, oxidative phosphorylation, phagosome, etc. The copper-stressed macrophages or neutrophils were revealed to have an increase in reactive oxygen species (ROS) and mitochondria ROS (mROS)-mediated apoptosis, and a reduction in phagocytosis. Furthermore, the A. hydrophila-infected copper-stressed macrophages or neutrophils were found to be unable to maintain a consistently increased expression in immune responsive genes. This study demonstrated for the first time that copper might induce the susceptibility of fish larvae to inflammatory stimuli via triggering macrophage or neutrophil apoptosis, leading to reduced phagocytic activities and non-sustainable immune responses in immune macrophages or neutrophils.

Keywords: copper, macrophages and neutrophils, phagocytosis, mROS, apoptosis, immune responses

\section{INTRODUCTION}

During zebrafish embryogenesis, primitive macrophages are initiated and specified at $12-16 \mathrm{hpf}$ (hours post fertilization) and primitive neutrophils at $16 \mathrm{hpf}(1,2)$ from rostral blood island (RBI) $(3,4)$. Functional macrophages and neutrophils can be recruited to the infected sites and phagocyte invading bacteria as early as 30 and $52 \mathrm{hpf}$, respectively $(5,6)$. Zebrafish rely exclusively on innate immune system before they form functional adaptive immunity at around $28 \mathrm{dpf}$ (days post fertilization) (6).

The neutrophils and macrophages, as hematopoietic leukocyte subsets in innate immune system in fish, form the first line of defense against the invasion of pathogens and the resultant diseases and mortalities. Recently, the zebrafish (Danio rerio) embryos and larvae have been proven to be unique 
vertebrate models for studying host-microbe interactions due to their advantages in in vivo imaging and genetic analysis $(7,8)$. However, to date, studies on host-microbe interaction in fish under a stressed environment are scarce, and little is known about the cellular biology and transcriptional responses of leukocyte cells to microbe infection in stressed fish.

Aeromonas hydrophila, a gram-negative opportunistic pathogen found in aquatic environment, is the main pathogen infecting farmed fish such as blunt snout bream (9), large yellow croaker (10), and gibel carp (Carassiu auratus gibelio) (11) in China. It has been found that the degradation of culture conditions, such as the increased stocking densities, poor water quality, etc., could increase the mortality rate of A. hydrophilainfected fish. However, the potential molecular mechanisms of A. hydrophila as an opportunistic pathogen in inducing fish mortality are still unknown.

It is widely known that excessive copper in aquatic environment can affect the development and survival of fish embryos and larvae (12-14). Copper also has a strong negative effect on the zebrafish hematopoietic system via reducing the hematopoiesis potential of head kidney (15), and excessive copper was associated with leukemia in human (16), suggesting the negative role of excessive copper in hematopoietic system and its immune response activity.

In this study, the gene expression profiles of GFP-positive cells in copper $\left(\mathrm{Cu}^{2+}\right)$ stressed $l y z$ and $m p x$ transgenic larvae in which GFP labeling of neutrophils at $68 \mathrm{hpf}$ and of those in corola transgenic larvae in which fluorescent GFP labeling of both neutrophils and macrophages at $68 \mathrm{hpf}$ were revealed by RNA-Seq. Furthermore, the responses of copper-stressed larvae and their macrophages and neutrophils to A. hydrophila infection were further investigated, and the reactive oxygen species (ROS)mediated apoptosis and the down-regulated phagocytic activities of neutrophils and macrophages were found to be associated with the sensitivity of copper-stressed fish larvae to A. hydrophila infection in this study.

\section{MATERIALS AND METHODS}

\section{Zebrafish Lines and Maintenance}

Adult zebrafish, including AB, $\operatorname{Tg}$ (corola:eGFP) (7), $\operatorname{Tg}$ (lyz:eGFP) (17), and $\operatorname{Tg}(m p x: \mathrm{eGFP})(18)$ (the three transgenic lines were kindly provided by Professor $\mathrm{Li} \mathrm{Li}$, Southwest University, China), were raised in recirculating aquaculture systems ( $28 \pm 0.5^{\circ} \mathrm{C}, 14: 10 \mathrm{~h}$ light:dark), and were fed with hatched fairy shrimps three times each day. Male and female zebrafish were kept separately until mating and spawning. Eggs from the same batch (spawned by several pairs of adult fish) were collected, washed, and staged by morphological features based on the morphological criteria as described by Kimmel et al. (19) and then were used for different treatments and experiments as described below. The age of embryos and larvae was expressed in hours post fertilization (hpf) or days post fertilization (dpf).

\section{Chemical Treatment}

In this study, $0.25 \mathrm{mg} / \mathrm{L} \mathrm{Cu}^{2+}(3.9 \mu \mathrm{M})$ was used to stress the zebrafish embryos and larvae. NAC ( $N$-acetylcysteine, Beyotime,
Suzhou, China) and GSH (reduced glutathione, GBCBIO Tec. Inc., Guangzhou, China) were dissolved in DMSO in the dark as stock solutions (20). In experiments of co-exposure with ROS scavenger, embryos were pretreated with $200 \mu \mathrm{M}$ NAC or $200 \mu \mathrm{M}$ reduced GSH (21) at the fertilization stage, and when embryos developed to the sphere stage ( $4 \mathrm{hpf}), \mathrm{Cu}^{2+}(3.9 \mu \mathrm{M})$ was added separately to the pretreated medium.

\section{Tail Wounding}

Embryos were collected and cultured in sterile pure water (egg water) instead of E3 water $(5.0 \mathrm{mM} \mathrm{NaCl}, 0.17 \mathrm{mM} \mathrm{KCl}$, $0.33 \mathrm{mM} \mathrm{CaCl}, 0.33 \mathrm{mM} \mathrm{MgSO}_{4}, 0.05 \%$ methylene blue, $\mathrm{pH}$ 7.4) to eliminate the influence from other ions in E3 medium as we performed previously (22-24). Larvae at $68 \mathrm{hpf}$ from the $\mathrm{Cu}^{2+}$-stressed group and the control group without $\mathrm{Cu}^{2+}$ stress were wounded at tail fin with a sterile 24-gauge needle under a Stereoscopic Microscope (Leica M250FA) in fresh sterile filtered egg water with $0.02 \%$ tricaine as previously reported $(7,25)$. The wounded embryos were used for further analysis, such as mortality rate, A. hydrophila infection, and neutrophil/macrophage recruitment.

\section{Bacterial Challenge}

In this study, A. hydrophila (isolated from blunt snout bream by assistant Professor Yi Luo) (26) was used to infect copperstressed larvae at $68 \mathrm{hpf}$ in two bath infection models: larvae were exposed to the bacteria in egg water by immersion only or immersion after injury. For the immersion only model, a trial test was performed first among $\mathrm{Cu}^{2+}$-stressed and no- $\mathrm{Cu}^{2+}$-stressed control larvae challenging with $A$. hydrophila infection beginning at $68 \mathrm{hpf}$ to determine the mortalities at the concentrations of bacterial cells $\left(10^{6}\right.$ and $\left.10^{7} \mathrm{cfu} / \mathrm{ml}\right)$, mimicking fish larvae under bacterial infection in a natural copper-stressed or no-copperstressed environment. Over 50 embryos were used in each group and three biological replicates were performed in this test.

The wounded larvae of $\mathrm{Cu}^{2+}$-stressed or the control without $\mathrm{Cu}^{2+}$ stress were infected with $A$. hydrophila at $68 \mathrm{hpf}$ via immersion post-injury model, and the migration dynamics of neutrophils/macrophages in the infected $\mathrm{Cu}^{2+}$-stressed and control larvae were analyzed separately at $0,2,4$, and 6 hpi (hours post infection).

\section{Live Imaging}

The wounded $\mathrm{Cu}^{2+}$-stressed and no- $\mathrm{Cu}^{2+}$-stressed control larvae after $A$. hydrophila infection were anesthetized and photographed separately using a Stereoscopic Microscope (Leica M250FA) with a fluorescent filter. A. hydrophila-infected and wounded larvae from $\mathrm{Cu}^{2+}$-stressed or control group (over 10 larvae/sample) were anesthetized and photographed at 0 hpi and then were cultured continuously under $A$. hydrophila-infected condition, and were further anesthetized and photographed at 2, 4, and 6 hpi separately. The numbers of GFP-labeled neutrophil/macrophage cells around the wounded locus (in red boxes) were counted and compared between $\mathrm{Cu}^{2+}$-stressed and no- $\mathrm{Cu}^{2+}$-stressed control larvae. In this study, red boxes for GFP-positive cell counting area were determined based on the wound loci in each larva as studies reported recently $(7,25)$, and 
the size of the red boxes was fixed for each larva in order to avoid the area variation for $\mathrm{GFP}^{+}$cell counting.

\section{Quantitative Real-Time PCR (qRT-PCR) in Whole Embryos}

Larvae were infected with $A$. hydrophila at $68 \mathrm{hpf}$, followed by collection at $6 \mathrm{hpi}$ for testing the immune responses in the whole larvae. Briefly, 30-50 embryos/sample were used for total RNA extraction with TRizol Reagent (Ambion, USA), and cDNA was synthesized using an M-MLV Reverse-Transcript Kit (ABM Inc., Canada). Quantitative PCR was performed using $\mathrm{iQ}^{\mathrm{TM}} \mathrm{SYBR}^{\circledR}$ Green Super mix (Bio-Rad Laboratories, USA) in a CFX Connect ${ }^{\mathrm{TM}}$ Real-Time PCR Detection System (Bio-Rad Laboratories, USA).

It has been reported that increased expression was observed in genes of $\operatorname{tr} 5 b(9), \operatorname{tnf} \alpha$, and $i l 1 \beta$ (27), and Toll-like receptor and JAK-STAT and MAPK pathways (10) in fish after A. hydrophila infection. Thus, in this study, the whole A. hydrophila-infected larvae were tested in the expression of the proinflammatory cytokine genes il-6, TLR signaling pathway genes (tlr5b, jun, myd88, trif, IkBa, nfkbia, erk1/2, jnk), MAPK pathway genes (dusp and racla), and other immune and stress responsive genes (stat1a, c3a, defb1, and $h s p 70.3$ ). Primer sequences for the aforementioned genes are shown in Table S1.

\section{RNA-Sequencing Analysis}

$T g$ (coro1a:eGFP), $T g$ (lyz:eGFP), and $T g(m p x$ :eGFP) larvae from the $\mathrm{Cu}^{2+}$-stressed group and the no- $\mathrm{Cu}^{2+}$ control group at 68 hpf were collected and washed, and then were dissociated into single cells by $1 \mathrm{ml}$ of homogenizer in solution of phosphate buffer saline (PBS) with 5\% fetal bovine serum (FBS). Then, the homogenized cells were filtered through a $70 \mu \mathrm{m}$ cell strainer as reported in literature $(28,29)$. Next, the GFP-positive cells $(100-$ 200 sorted cells/sample) of different lines from the $\mathrm{Cu}^{2+}$-stressed and control larvae were sorted separately by flow cytometry (FACS) (BD FacsAria SORP, 650110M3, BioDot, American) and the background fluorescence in cells from WT (wild type) fish without transgenic GFP was used as gate determination for GFP-positive cell sorting in this study.

The 100-200 sorted GFP-positive cells for each sample were then lysed in SMART-SeqTM V4 kit lysis buffer provided by Novogene Company. Next, the high-quality next-generation sequencing libraries for each sample (the sorted 100-200 sorted GFP cells) were constructed from as little as $10 \mathrm{pg}$ total RNA by the Kit. Finally, the constructed libraries were sequenced using an Illumina HiSeqTM in Novogene Company.

Normalized read counts were used for fold change analysis, and fold changes were determined for each gene through dividing the number of tags in the normalized $\mathrm{Cu}^{2+}$-stressed libraries by that in the normalized control libraries by DEGSeq. Genes that were significantly altered as a result of the $\mathrm{Cu}^{2+}$ stresses (adjusted $P<0.05)$ were defined as differentially expressed genes (DEGs) and were used for further analysis. Pathway analysis and enriched KEGG pathways were conducted using KOBAS v2.0 based on the lists of DEGs (adjusted $P<0.05$ ) for each of the treatments and lines. Hierarchical clustering was performed by TIGR Multi experiment Viewer $(\mathrm{MeV})$ to generate different Heatmaps.

\section{Apoptosis Assay}

$T g$ (corola:eGFP), $\operatorname{Tg}($ lyz:eGFP), and $T g(m p x: e G F P)$ larvae from the $\mathrm{Cu}^{2+}$-stressed and control groups (100 larvae/sample) at 68 hpf were dissociated separately into single cells as mentioned above, and the dissociated single cells for each sample were separately used for Annexin V-PE and DAPI (4',6-diamidino-2phenylindole) (Beyotime Biotechnology) co-staining according to the instructions provided in the Annexin V-PE apoptosis assay kit (Beyotime Company, China). Then, the stained cells were used for analysis of cell apoptosis by FACS (CytoFLEX S, Beckman Coulter, USA). DAPI was used to distinguish dead vs. live cells. Additionally, propidium iodide (PI) staining for the aforementioned cells was used to distinguish the Annexin V-PE positive cells in terms of apoptosis, necroptosis, or pyroptosis in this study. For FACS analysis, background fluorescence was determined using the embryonic cells without reagent (Annexin V-PE, DAPI, or PI) staining. Three biological replicates were performed for each test, respectively, in this study.

\section{Phagocytosis Analysis}

The aforementioned transgenic larvae from the $\mathrm{Cu}^{2+}$. stressed group and the no- $\mathrm{Cu}^{2+}$-stressed control group (100 larvae/sample) at $68 \mathrm{hpf}$ were dissociated separately into single cells, followed by incubation with pHrodo ${ }^{\mathrm{TM}}$ Red BioParticles ${ }^{\circledR}$ Conjugates Reagent (Molecular Probes, Life Technologies, Cat\#P35361) at $28^{\circ} \mathrm{C}$ in the dark for over $30 \mathrm{~min}$ according to the manual instructions. The reagent is actually a kind of $E$. coli bioparticle that could be easily ingested by macrophages and neutrophils. The cells with uptake bacteria will exhibit red fluorescence, and the red fluorescence intensity depends on the surrounding acidic $\mathrm{pH}$ in cells. Next, the stained cells were used for analysis of red fluorescence intensity and percentage of red/GFP double-positive cells in the total GFP-positive cells by FACS (BD FacsAria SORP, 650110M3, BioDot, American), and the background fluorescence was determined using the samples that contain the pHrodo BioParticles but no macrophage and neutrophil cells.

In order to test the phagocytic activity of each macrophage or neutrophil in the control or copper-stressed embryos, the red and GFP double-positive cells were sorted separately from the $\mathrm{Cu}^{2+}$. stressed dissociated cells and the control, followed by collection and fixing with standard 2-4\% paraformaldehyde (PFA) solution. Finally, the fixed red and GFP double-positive cells were smeared on slide glasses and observed under a Leica confocal microscope (Olympus FV1000 Confocal Microscope, Japan).

\section{ROS Detection}

The aforementioned transgenic larvae from the $\mathrm{Cu}^{2+}$-stressed group and the control group (100 larvae/sample) at $68 \mathrm{hpf}$ were dissociated separately into single cells as mentioned above, followed by incubation with the Fluorometric Intracellular ROS kit (Deep Red Fluorescence, Sigma-Aldrich, Cat\# MAK142) according to the manual instructions. Finally, the isolated and stained cells were analyzed by FACS (CytoFLEX S, Beckman Coulter, USA). In this study, the FACS gate was determined based on the background fluorescence using a sample that contains 
the embryonic cells without the ROS Deep Red Fluorescence reagent staining.

\section{One Step Cell-Direct qRT-PCR}

Larvae from the control and $\mathrm{Cu}^{2+}$-stressed groups were infected with A. hydrophila at $68 \mathrm{hpf}$, and the macrophages and neutrophils in both infected and uninfected larvae (100 larvae/sample) were sorted separately by FACS (BD FacsAria SORP, 650110M3, BioDot, American) at 6 or 24 hpi for cell direct quantitative real-time PCR (qRT-PCR) of immune and apoptosis genes. Briefly, the GFP-positive cells were sorted and lysed in solution provided by CellsDirect ${ }^{\mathrm{TM}}$ One-Step qRTPCR Kit (Invitrogen, Cat\#11753-100). Finally, the lysed solution was used as template for one step cell direct qRT-PCR using CellsDirect $^{\mathrm{TM}}$ One-Step qRT-PCR Kit (Invitrogen) as reported previously $(30,31)$. Primer sequences for the genes tested in this study are shown in Table $\mathbf{S} 1$.

\section{Statistical Analysis}

Larvae with different treatments were collected at the indicated stages as described above. The sample size and the biological replicates for each test were also mentioned above. Results of mortalities, FACS indicating phagocytosis, ROS, apoptosis, and qPCR were analyzed using one-way analysis of variance (ANOVA) and post-hoc Tukey's test on Statistic Package for Social Science (SPSS) 19.0 software. Comparison analyses of cell numbers around wounded locus and phagocytic E. coli number in each cell were performed using hypergeometric distribution in R-console software. Statistically significant differences between groups were indicated by ${ }^{* * *} P<0.001,{ }^{* *} P<0.01,{ }^{*} P<0.05$, and ns, no significance.

\section{RESULTS}

\section{Increased Mortality Occurs in Copper-Stressed Larvae After $\boldsymbol{A}$. hydrophila Infection}

The growth curve of $A$. hydrophila used in this study is shown in Figure S1. Larvae at $68 \mathrm{hpf}$ were infected with $A$. hydrophila at the concentration of $10^{6} \mathrm{cfu} / \mathrm{ml}$ by immersion only. At $6 \mathrm{hpi}$, the whole larvae showed increased expression in proinflammatory cytokines il-6, TLR signaling pathway genes tlr5b, jun, myd88, trif, IkBa, nfkbia, erk1/2, jnk, MAPK pathway genes dusp and racla, and other immune and stress responsive genes like stat $1 a, c 3 a$, $d e f b 1$, and hsp70.3 (Figure 1A).

Larvae from the control and $\mathrm{Cu}^{2+}$-stressed groups at $68 \mathrm{hpf}$ were infected separately with $A$. hydrophila at concentrations of $10^{6}$ and $10^{7} \mathrm{cfu} / \mathrm{ml}$. The $\mathrm{Cu}^{2+}$-stressed group showed a significant increase in mortality from $5.0 \pm$ $0.5 \%$ to $25.0 \pm 4.5 \%$ from 12 hpi to afterword (Figure 1B). Overall, the mortality in $\mathrm{Cu}^{2+}$-stressed larvae increased significantly with the increasing infection concentration of A. hydrophila (Figure 1B).

The mortalities of larvae in different groups were compared in terms of $A$. hydrophila infection manner: immersion only or immersion post injury. Specifically, in copper-stressed larvae, infection by immersion only with $A$. hydrophila at $10^{7} \mathrm{cfu} / \mathrm{ml}$ showed $20.0 \pm 2.0 \%$ mortality at $12 \mathrm{hpi}$ and $25.0 \pm 4.5 \%$ at $24 \mathrm{hpi}$ and later, in contrast to $0 \%$ in the control group. Meanwhile, infection by immersion post injury at $10^{7} \mathrm{cfu} / \mathrm{ml}$ exhibited $10.0 \pm 0.5 \%$ to $25.0 \pm 2.0 \%$ mortality in the $\mathrm{Cu}^{2+}$ stressed group at $12-72 \mathrm{hpi}$, which was significantly higher than that $(5.0 \pm 0.5 \%$ to $10.0 \pm 2.0 \%)$ in the control injury group (Figure 1C).

\section{Copper-Stressed Neutrophils and Macrophages Respond Quickly to A. hydrophila Infection}

At $68 \mathrm{hpf}$, the transgenic zebrafish larvae of corola-GFP, lyz-GFP, and $m p x$-GFP were infected with $A$. hydrophila via immersion only, and no obvious distribution change was observed in corolaGFP, $l y z$-GFP, or $m p x$-GFP cells in the larvae from the control and the copper-stressed groups at $24 \mathrm{hpi}$ after A. hydrophila infection (Figures S2A-C).

Under no $A$. hydrophila infection condition, compared with the control corola promotor-driven GFP transgenic larvae, the percentage of GFP-positive cells showed a significant decrease from $2.68 \pm 0.20 \%$ to $1.52 \pm 0.21 \%$ in $\mathrm{Cu}^{2+}$-stressed larvae (Figures 2A1,A2,B). Additionally, the $\mathrm{Cu}^{2+}$-stressed larvae rather than the control exhibited a significant increase in the percentage of neutrophil and macrophage cells at $4 \mathrm{~h}$ post A. hydrophila infection (Figures 2A1-A4,B). At $24 \mathrm{hpi}$, the percentage of GFP-positive cells showed no difference in $\mathrm{Cu}^{2+}$ stressed corola larvae (Figures 2A5-A8,B), in contrast to a significant reduction in the percentage of GFP-positive cells in the control larvae after A. hydrophila infection (Figures 2A5-A8,B). Furthermore, the percentages of GFP neutrophil cells in $l y z$ transgenic larvae were significantly increased in $\mathrm{Cu}^{2+}$-stressed larvae at $4 \mathrm{~h}$ post both with and without $A$. hydrophila (72 hpf) infection (Figures S2D,E), and A. hydrophila infection significantly down-regulated the percentage of the lyz-GFPpositive cells in both the control and the $\mathrm{Cu}^{2+}$-stressed larvae at 92 hpf (24 hpi) (Figures S2D,E).

The infection model of immersion after injury was used to test the recruitment response of neutrophils and macrophages to $A$. hydrophila infection, and the experimental schematic is shown in Figure 3A. After marking both macrophages and neutrophils in zebrafish larvae with $\mathrm{Tg}$ (corola:eGFP) at $68 \mathrm{hpf}$, corolaGFP-positive cells were recruited around the wounded domain from 0 h post $A$. hydrophila infection (Figures 3B,C), and corolaGFP-positive cells in the $\mathrm{Cu}^{2+}$-stressed larvae responded more rapidly to $A$. hydrophila infection (Figures 3B,C) than the cells in the control larvae. Additionally, more corola-driven macrophage and neutrophil cells in $\mathrm{Cu}^{2+}$-stressed embryos were recruited to the infection and wounded domain from 0 to 6 hpi (Figures 3B,C).

Neutrophils driven by $l y z$ or $m p x$ promotor exhibited only slightly quicker responses in $\mathrm{Cu}^{2+}$-stressed larvae and were recruited to the infected locus more rapidly from 0 to $4 \mathrm{~h}$ post A. hydrophila infection, but exhibited no significant difference in larvae between the $\mathrm{Cu}^{2+}$-stressed and control groups at $6 \mathrm{hpi}$ (Figures 3D,E and Figure S3). 


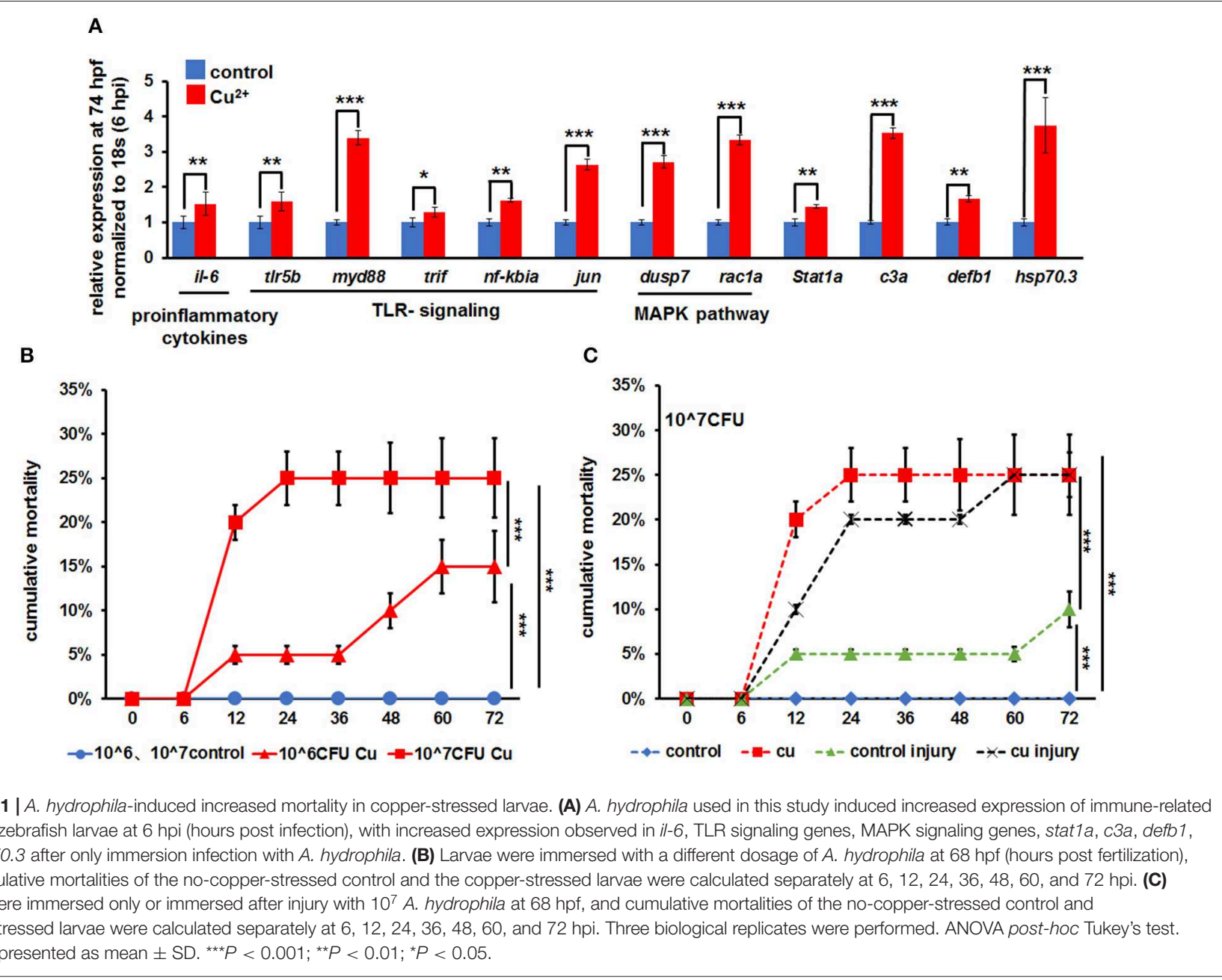

\section{Transcriptional Profiles in Neutrophils and Macrophages}

Cell imaging observations suggest that more rapid recruitment responses of macrophage and neutrophil cells to the infection locus occurred in $\mathrm{Cu}^{2+}$-stressed larvae. In an effort to explore how copper influences the immune responses of neutrophil/macrophage to A. hydrophila infection, we further examined the transcriptional profiles of neutrophils and macrophages in copper-stressed embryos. The corola-, mpx, or lyz-driven GFP-positive cells in the copper-stressed and control larvae at $68 \mathrm{hpf}$ were sorted by FACS and used for RNA-seq (100-200 cells/sample) (Figure 4A). Over 27.7, 24.9, and 21.8 million sequences were obtained for $\mathrm{Cu}^{2+}$-stressed corola, $m p x$, or lyz driven GFP-positive cells, respectively, and $25.5,31.5$, and 24.5 million sequences for their control cells, respectively (Table S2). The error rate and GC content for RNA sequencing reads were determined, and the results are shown in Figure S4 (error rates) and Figure S5 (GC contents), respectively. The classifications of raw reads for different samples are shown in Figure S6. Moreover, results of FPKM distribution and Pearson correlation analysis are shown in Figures S7, S8, respectively, and the Pearson correlation values were $0.896,0.928$, and 0.885 for corola, $m p x$, or $l y z$ cells, respectively.

DEGs were screened by DEGSeq and their Canoplot figures are shown as $\mathrm{Cu}^{2+} v s$ control for corola (Figure S9), $m p x$ (Figure S10), and lyz cells (Figure S11), respectively. The overlapping DEGs for the corola-, $m p x$-, and lyz-positive GFP cells were then used for KEGG enrichment analysis. Enrichment was detected in lysosome, apoptosis, oxidative phosphorylation, phagosome, proteasome, etc. Additionally, JakSTAT signaling, Wnt signaling, TGF-beta signaling, Notch signaling, and VEGF signaling were also enriched for the overlapping DEGs in all the three lines in copper-stressed larvae (Figures 4B,C and Tables S3-S8).

\section{Copper Down-Regulates Phagocytosis of Neutrophils and Macrophages}

Cell RNA-Seq results revealed the up-regulated expression of lysosome genes and the down-regulated expression of proteasome genes in copper-stressed corola-positive cells (Figures S12A,B), the down-regulated expression of both lysosome and phagosome genes in copper-stressed $m p x$-positive cells (Figures S12C,D), and the up-regulated expression of 


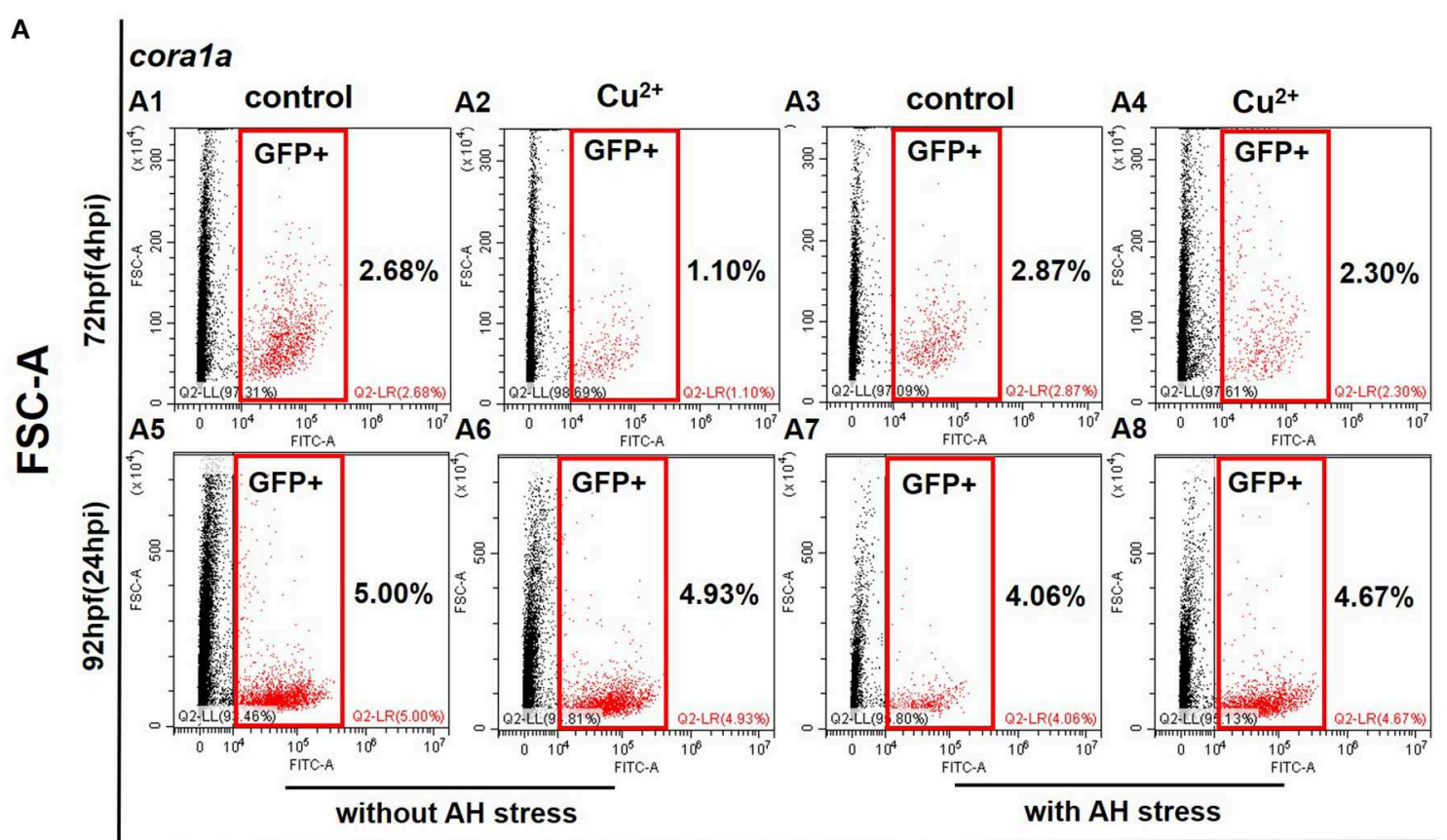

B

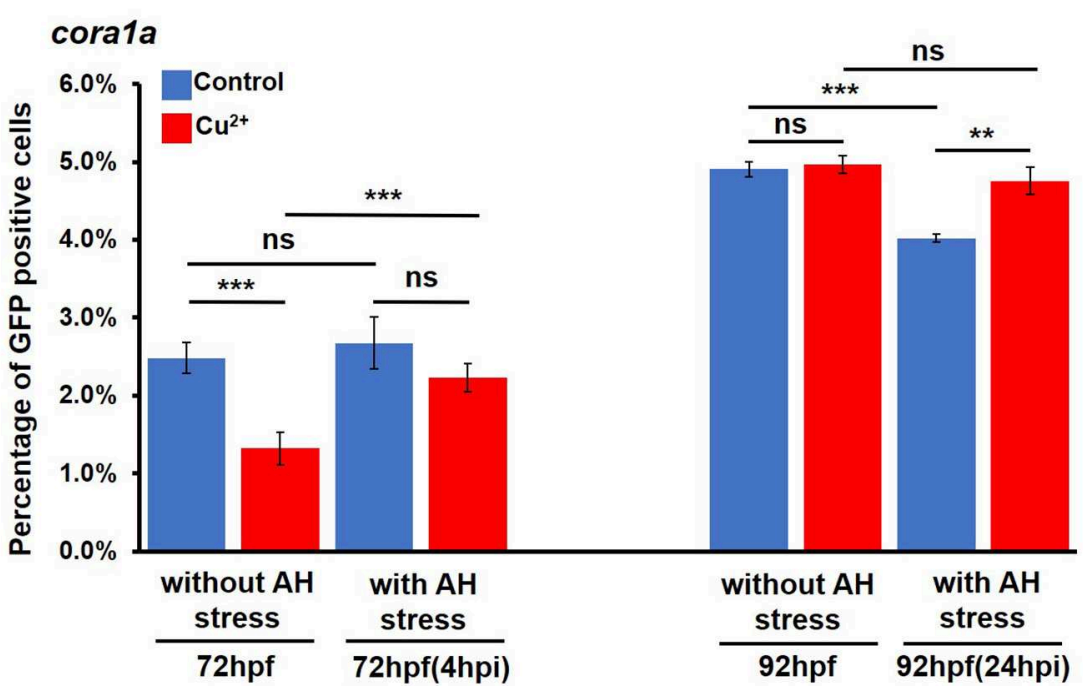

FIGURE 2 | Percentages of coro1a promotor-driven GFP-positive cells in copper-stressed and the no-copper-stressed control larvae before and after A. hydrophila infection. FACS (flow cytometry) plots (A1-A8) (red boxes indicating GFP-positive cells) and percentages (B) of coro1a promotor-driven GFP-positive macrophages and neutrophils in copper-stressed and control larvae with or without A. hydrophila infection. Three biological replicates were performed. ANOVA post-hoc Tukey's test. Data are presented as mean $\pm \mathrm{SD}$. ${ }^{\star \star \star} P<0.001$; ${ }^{\star \star} P<0.01$; and ns, no significance.

both lysosome and phagosome genes in copper-stressed lyzpositive cells (Figures S12E,F). Meanwhile, cell direct qRT-PCR detection showed the increased expression of the representative proteasome and lysosome genes in corola-, lyz-, and $m p x-$ positive cells in copper-stressed larvae (Figure S12G). However, the percentage of $\mathrm{PHrodo}^{\mathrm{TM}}$ red positive cells was downregulated significantly from $37.95 \pm 3.99 \%$ in the control corolaGFP-positive cells to $24.34 \pm 3.75 \%$ in the copper-stressed coro1a-positive cells (Figures 5A1-A3), and the percentage of red/GFP double-positive cells was down-regulated significantly from $45.13 \pm 4.00 \%$ to $20.18 \pm 6.50 \%$ in the control and copperstressed lyz-GFP-positive cells, respectively (Figures 5A4-A6).

Additionally, Red/GFP double-positive cells from the copperstressed and the control larvae were sorted by FACS and smeared on slide glasses for confocal observation to test bacterial numbers in each neutrophil or macrophage cell (Figure 5B). In corolaGFP-labeled cells, 3-6 red E. coli-positive dots were observed in the no-copper-stressed control neutrophils or macrophages cells (Figures 5C1,C2,C5) in contrast to about 1-2 red E. coli-positive dots observed in copper-stressed neutrophils or macrophages 

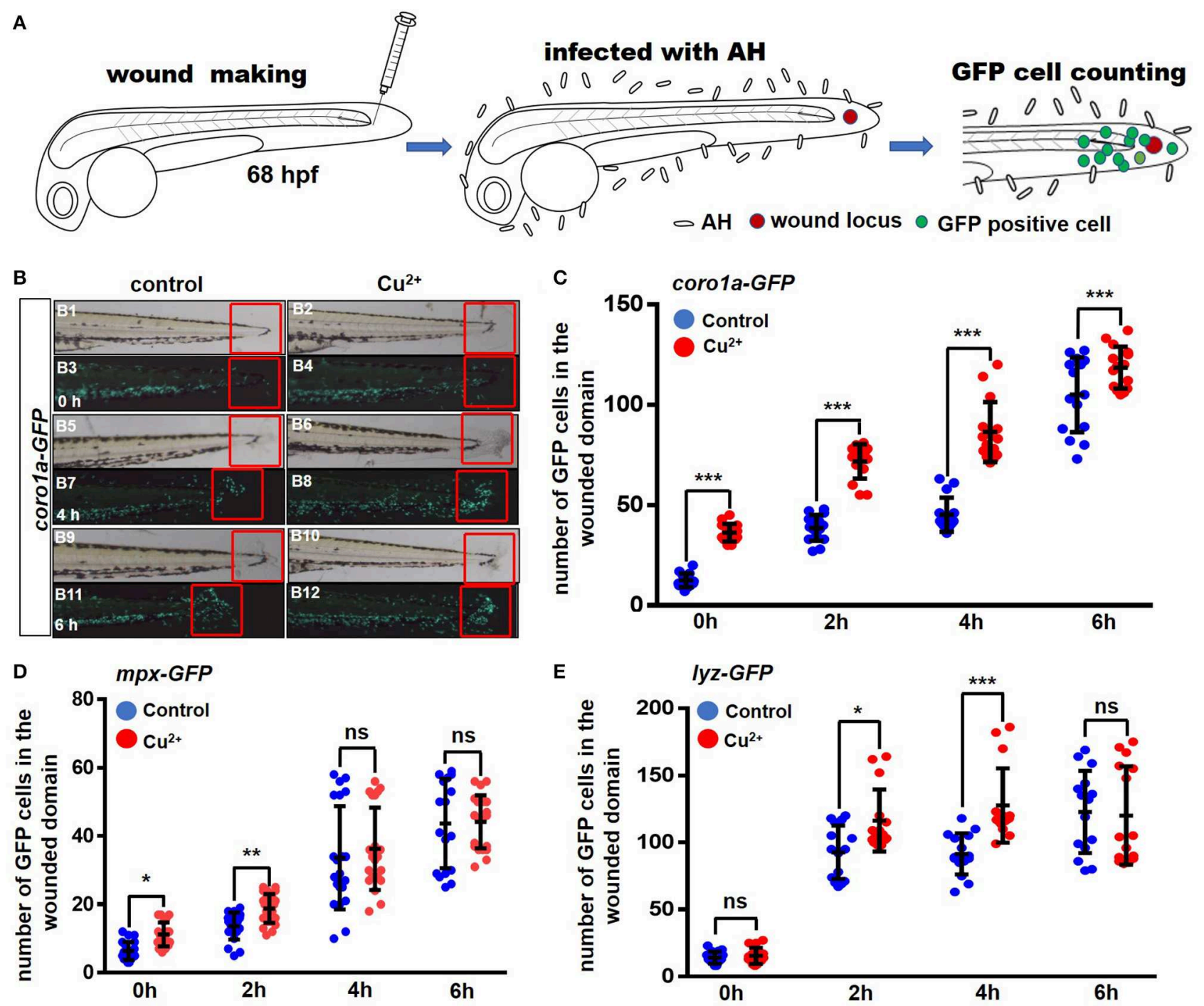

FIGURE 3 | Copper-stressed macrophages and neutrophils respond more quickly to A. hydrophila infection. (A) Schematic view of tail injury, A. hydrophila infection, and GFP-positive cell counting, with immersion after injury being used in the assays. (B) The recruitment of GFP-positive macrophages and neutrophils around injury locus (in the fixed red boxes) were analyzed at 0, 2, 4, and 6 hpi, using Tg (coro1a:eGFP) transgenic fish. (C-E) Quantification analysis showed a significant increase in the number of GFP-positive cells in the area near the injury locus in the copper-stressed Tg(coro1a:eGFP) larvae compared with the no-copper-stressed control at 0 , 2, 4, and 6 hpi (C), in the copper-stressed Tg (mpx:eGFP) larvae (D), and in the copper-stressed Tg (lyz:eGFP) larvae (E). Three biological replicates were performed. Analysis with hypergeometric distribution in R-console software for bi-modal distribution to exhibit individual variations in each group in one experiment. Data are presented as mean $\pm \mathrm{SD}$. ${ }^{\star \star \star} P<0.001$; ${ }^{\star \star} P<0.01$; ${ }^{*} P<0.05$; and ns, no significance.

(Figures 5C3-C5), indicating that phagocytic activities were significantly down-regulated in copper-stressed neutrophil or macrophages (Figure 5C5). In 1yz-GFP-labeled cells, $\sim 2-6$ red $E$. coli-positive dots were observed in control neutrophils (Figure 5C6), in contrast to about 1-3 red E. coli-positive dots observed in copper-stressed neutrophils (Figure 5C6).

\section{Copper Specifically Induces Neutrophil and Macrophage Apoptosis in Zebrafish Embryos}

Apoptosis signaling was enriched for the DEGs in copperstressed coro1a-, $m p x$-, and lyz-positive GFP cells (Figure 4), and clustering was performed for DEGs in apoptosis signaling in copper-stressed neutrophil and macrophage cells (Figure S13). This enabled us to further investigate the mechanism of copper in regulating the embryonic susceptibility to bacterial infection by measuring the apoptosis of GFP-labeled macrophage and neutrophil cells with annexin $\mathrm{V}(\mathrm{red}) / \mathrm{DAPI}$ (blue) co-staining and PI staining. We found that corola-, $m p x$-, and lyz-driven GFP-positive cells all exhibited a significantly increased level of apoptosis in $\mathrm{Cu}^{2+}$-stressed larvae, with the percentages of labeled cells reaching $63.82 \pm 2.20 \%, 86.55 \pm 5.30 \%$, and $82.30 \pm 6.20 \%$, in contrast to $6.78 \pm 2.64 \%, 5.75 \pm 2.12 \%$, and $10.23 \pm 3.25 \%$ in the control larvae, respectively (Figure 6A). PI staining was used to distinguish the annexin $\mathrm{V}$ red/GFP double-positive cells 


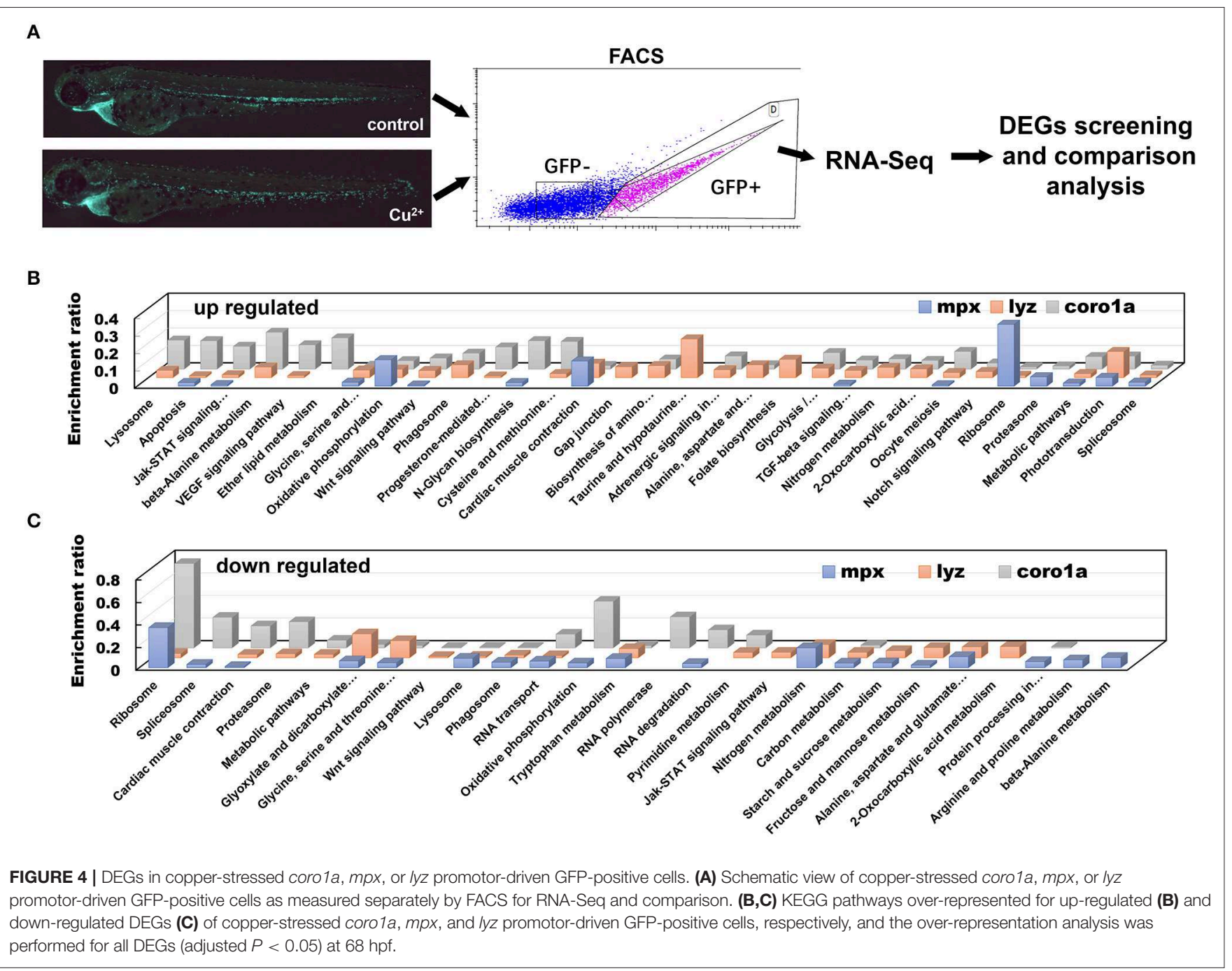

in terms of apoptosis, pyroptosis, or necroptosis in $\mathrm{Cu}^{2+}$-stressed larvae, with pyroptotic and necroptotic cells being annexin $\mathrm{V}$ and PI double-positive, and early apoptotic cells being annexin $\mathrm{V}$ positive but PI negative. No significant difference of PI level was observed between $\mathrm{Cu}^{2+}$-stressed and control larvae for all corola-, lyz-, and mpx-driven GFP-positive cells, and the percentages of PI positive cells were all around 10\% (Figure 6B and Figure S14A).

However, GFP-negative cells in $\mathrm{Cu}^{2+}$-stressed larvae showed a slightly significant increase in annexin $\mathrm{V}$-positive cells between $\mathrm{Cu}^{2+}$-stressed and control groups for the corola, lyz, and $m p x$ transgenic lines, which was $3.53 \pm 0.72 \%, 3.33 \pm$ $0.43 \%$, and $2.39 \pm 0.53 \%$ in copper-stressed larvae vs. 0.04 $\pm 0.01 \%, 0.04 \pm 0.01 \%$, and $0.13 \pm 0.09 \%$ in control larvae, respectively (Figures S14B,C).

\section{Copper-Induced ROS Triggers Neutrophil and Macrophage Apoptosis in Zebrafish Embryos}

Cell RNA-Seq analysis revealed down-regulation of genes in oxidative phosphorylation in corola but up-regulation in both $m p x$ - and lyz-positive cells in copper-stressed embryos (Figures S15A-C). Meanwhile, significant up-regulation was observed in the expression of oxidative phosphorylation genes, such as cox4il, $\operatorname{cox} 6 c, \operatorname{cox} 8 a, \operatorname{cox} 7 b$, atp $6 v 0 c b$, etc., in all corola-, $m p x-$, and lyz-positive cells in copper-stressed larvae in this study (Figure S15D).

We further measured the ROS levels and the expression of functional ROS-triggered apoptosis genes in neutrophil and macrophage cells in copper-stressed larvae. The ROS level was $\sim 3$.3-fold higher in corola-positive neutrophil and macrophage cells (Figures 7A2,A5) than in the control (Figures 7A1,A5), and the increased ROS level in copper-stressed neutrophil and macrophage cells could be recovered to nearly normal level by ROS scavengers NAC and GSH (Figures 7A1-A5). Additionally, a significant increase was observed in the ROS levels in copperstressed $m p x$ - and lyz-positive cells, and ROS scavengers NAC could significantly down-regulate the ROS levels in those copperstressed cells (Figure S16).

In this study, the expressions of ROS-mediated apoptosis signaling genes were further tested, and Figure $7 \mathbf{B}$ shows the 


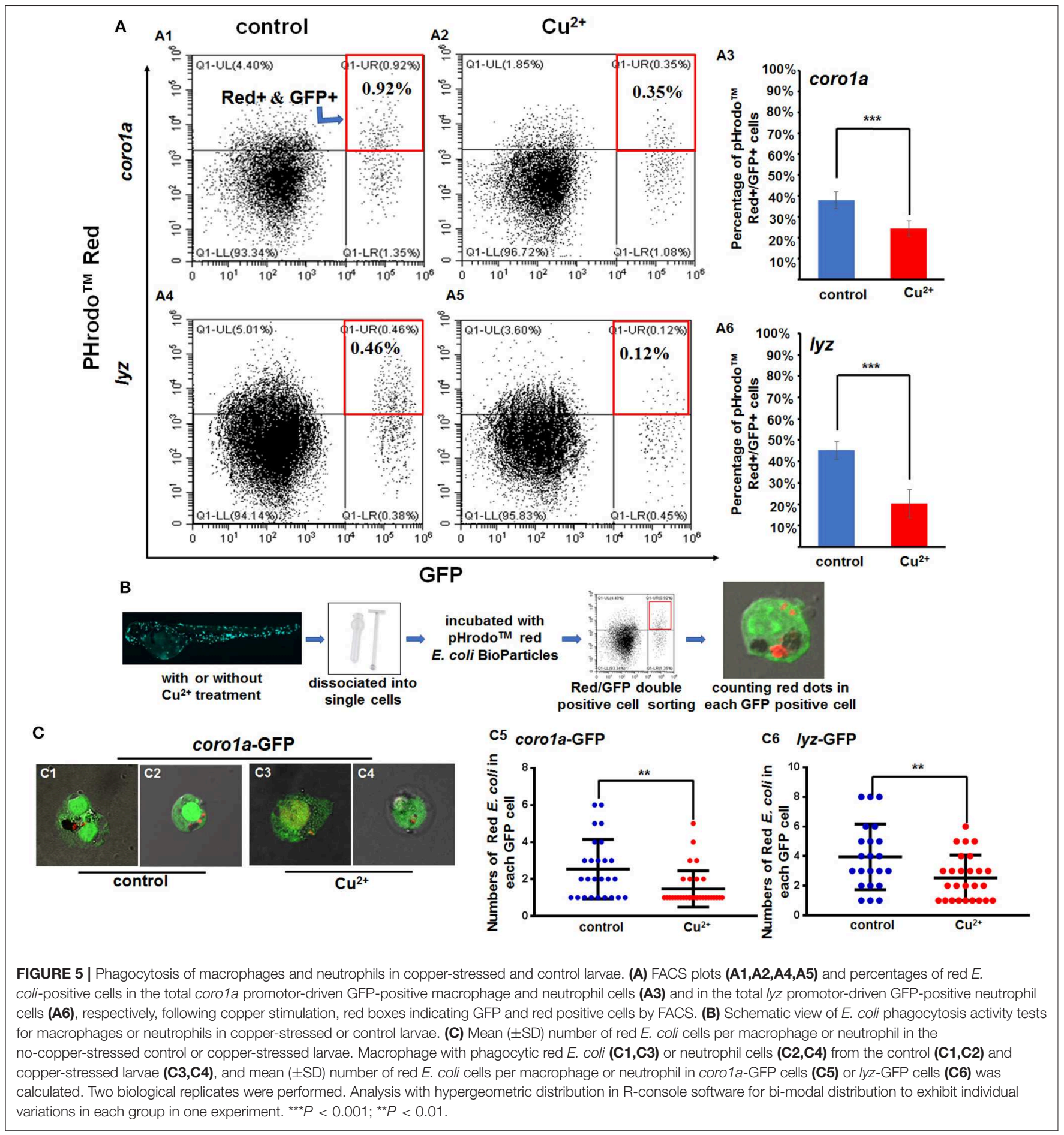

schematic of cell direct qRT-PCR detection of apoptosis signaling genes in neutrophil and macrophage cells. The expression was significantly increased in caspase8, caspase9, caspase3, and caspase6, but normal in caspase7, caspase2, and caspase 10 in both copper-stressed corola-GFP-positive cells (Figure 7C) and $m p x$ - and lyz-GFP-positive cells (Figures S17A1, S18A1). Additionally, genes $b c l-2, b i d$, and $b a d$, which function in mitochondrial ROS (mROS)-associated apoptosis signaling, exhibited significantly increased expression in copper-stressed corola-positive cells (Figure 7D). Moreover, a significant increase was observed in the expression of the aforementioned mROS-associated apoptosis signaling genes in both copperstressed $m p x$-positive cells (Figure S17A2) and lyz-positive cells (Figure S18A2). 


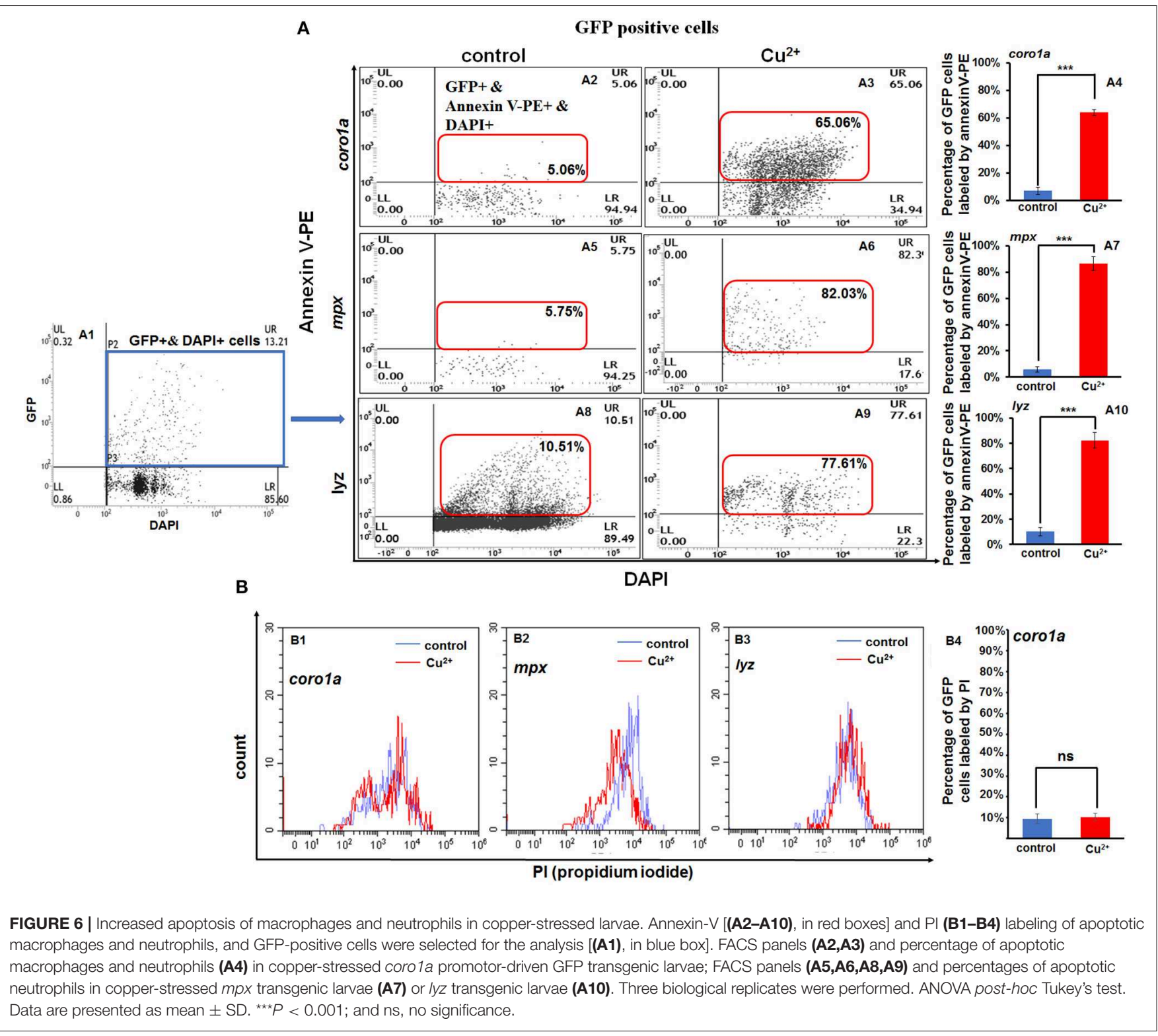

\section{Immune-Related Gene Expression in Copper-Stressed}

\section{Neutrophils/Macrophages Cells}

Cell RNA-Seq analysis revealed that Jak-STAT signaling, which has important function in immune responses to bacterial infection (10), was enriched for DEGs in copper-stressed corola, $m p x$-, and lyz-positive cells (Figure 4). Thus, we examined further whether immune responses also contribute to the susceptibility of copper-stressed larvae to A. hydrophila infection. A significant up-regulation was found in the expression of heat shock responsive gene $h s p 70.3$, and immune responsive genes, such as TLR signaling genes myd88, jun, $t l r 5 b$, and $n f k b 1 a$, MAPK pathway genes max and $r a c l a$, and immune transcriptional factor stat 1a in copper-stressed corola promotor-driven GFP-positive cells (Figure 8A). However, the expression was significantly down-regulated in several aforementioned genes, such as myd88, jun, max, or racla in either $m p x$ - or lyz-positive cells from copper-stressed larvae (Figures 8B,C).

\section{Expression of Apoptosis and Immune-Related Genes in Copper-Stressed Neutrophils/Macrophage Cells After A. hydrophila Infection}

The expression of the aforementioned genes in mitochondriaassociated apoptosis signaling and in immune responses was further tested by cell direct qRT-PCR in copper-stressed neutrophil and macrophage cells after A. hydrophila infection. Caspase 9 still exhibited a slight increase of expression in corola-, $m p x$-, or lyz-positive cells in copper-stressed larvae at 6 and 24 


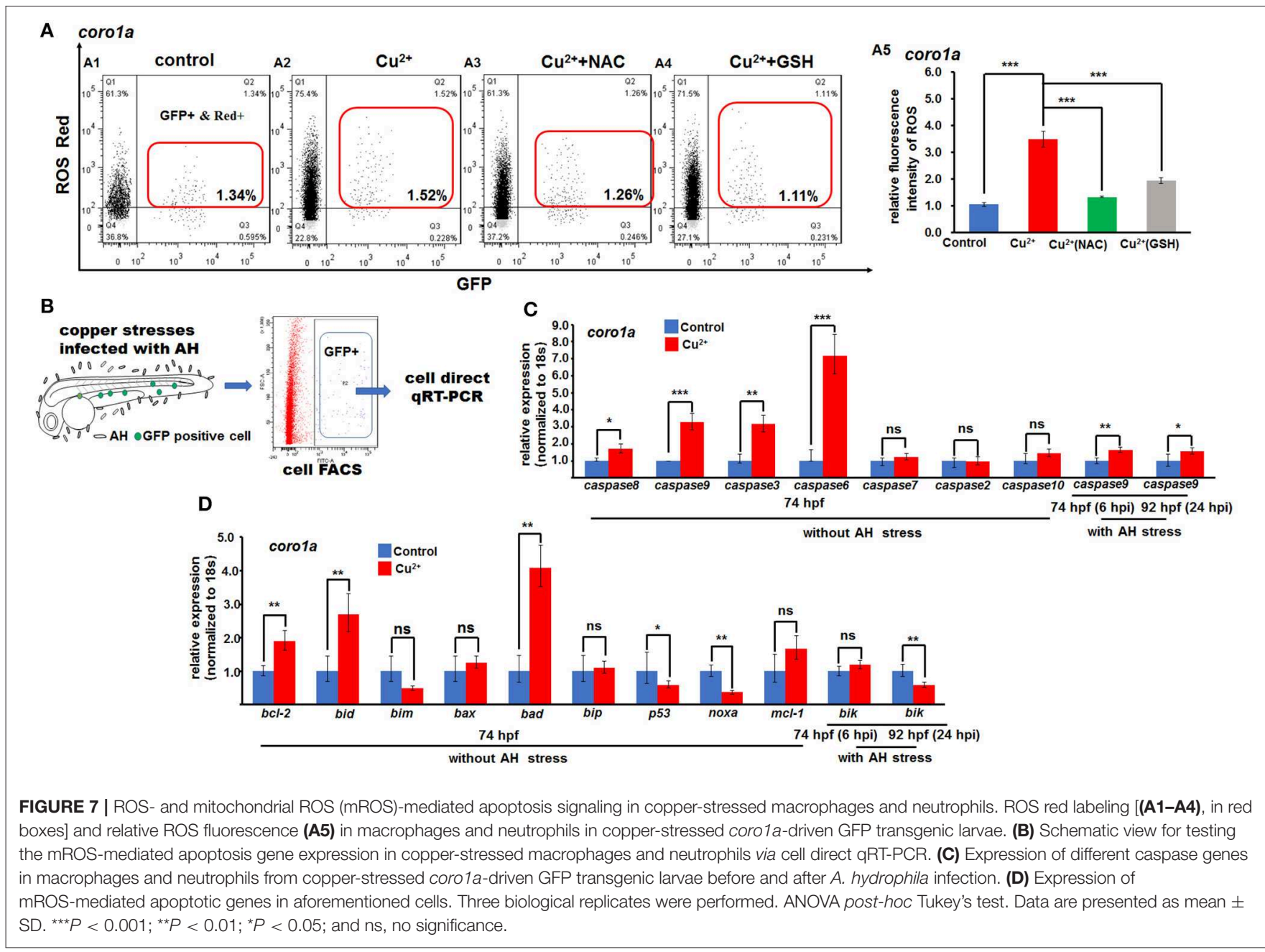

hpi (Figure 7C and Figures S17A1, S18A1). However, apoptosis signaling gene bik exhibited no change or even down-regulation of expression in corola-, $m p x$-, and lyz-positive cells at 6 or 24 hpi (Figure 7D and Figures S17A2, S18A2).

In copper-stressed corola-positive cells, the expression of the inflammatory cytokine ill $\beta$ was down-regulated at $6 \mathrm{hpi}$ and was significantly down-regulated at $24 \mathrm{hpi}$ (Figures 9A1,A2). Additionally, the expression of TLR signaling pathway gene tlr $5 b$ was significantly down-regulated at 6 hpi (Figure 9A1), in contrast to a significant up-regulation in the expression of MAPK pathway genes $d u s p 7$ and $\max$ (Figure 9A1), and a slight increase in the expression of stat 1a, an important transcriptional factor in immune responses (Figure 9A1). At $24 \mathrm{hpi}$, the expression of TLR pathway genes tlr5b and $n f-k b i a$ exhibited no significant changes, but the signaling gene jun was significantly down-regulated (Figure 9A2). Moreover, MAPK pathway genes $d u s p 7, \max$, and rac1a all exhibited significantly down-regulated expression, and so did stat1a (Figure 9A2).

The expression of the aforementioned genes was further tested in copper-stressed $m p x$ - and lyz-positive cells. At $6 \mathrm{~h}$ post A. hydrophila infection, a significant up-regulation was observed in the expression of TLR pathway genes tlr5b as well as MAPK pathway genes dusp7, max, and racla in copperstressed $m p x$-positive cells (Figure 9B1) and lyz-positive cells (Figure 9C1). An increased expression was also shown in the inflammatory cytokine $i l 1 \beta$ and immune transcriptional factor stat1a (Figures 9B1,C1). At 24 hpi, genes jun and racla exhibited significantly down-regulated expression in copper-stressed $m p x$ positive cells (Figure 9B2). Meanwhile, an increased expression was observed in TLR and MAPK pathway genes, inflammatory cytokine il1 $\beta$, and immune transcriptional factor stat $1 a$ in copper-stressed lyz-positive cells (Figure 9C2).

\section{DISCUSSION}

A. hydrophila is a gram-negative opportunistic pathogen found in aquatic environment, but the potential molecular mechanisms of how it functions as an opportunistic pathogen in inducing fish mortality are still scare. Additionally, excess copper induces the degradation of culture condition as well as increased fish mortality and reduces fish hematopoiesis potentiality; however, the potential mechanisms and the mechanism linkages are still limited. This study, for the first time, not only linked 


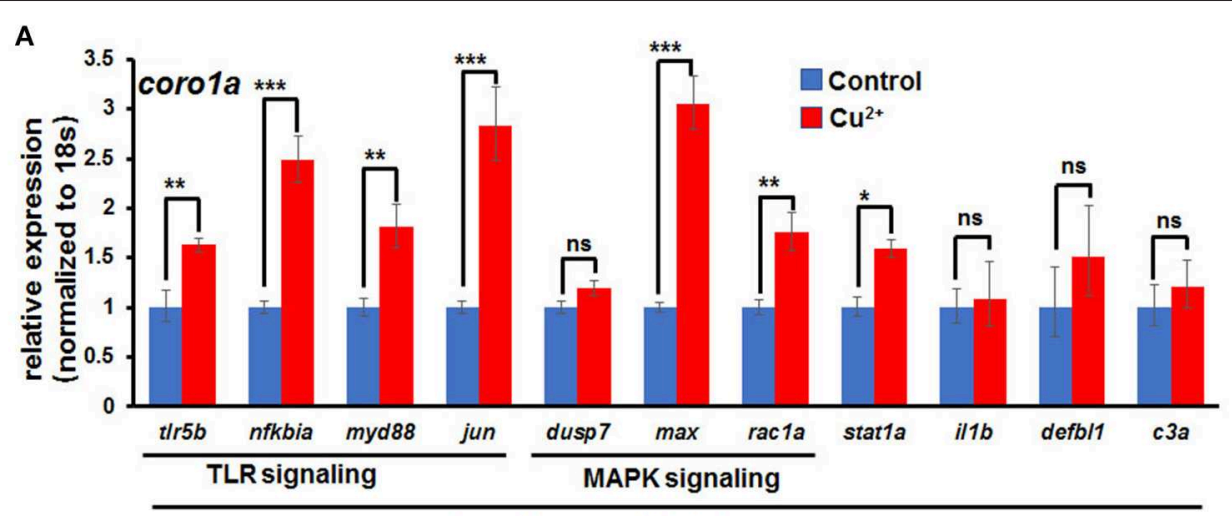

B
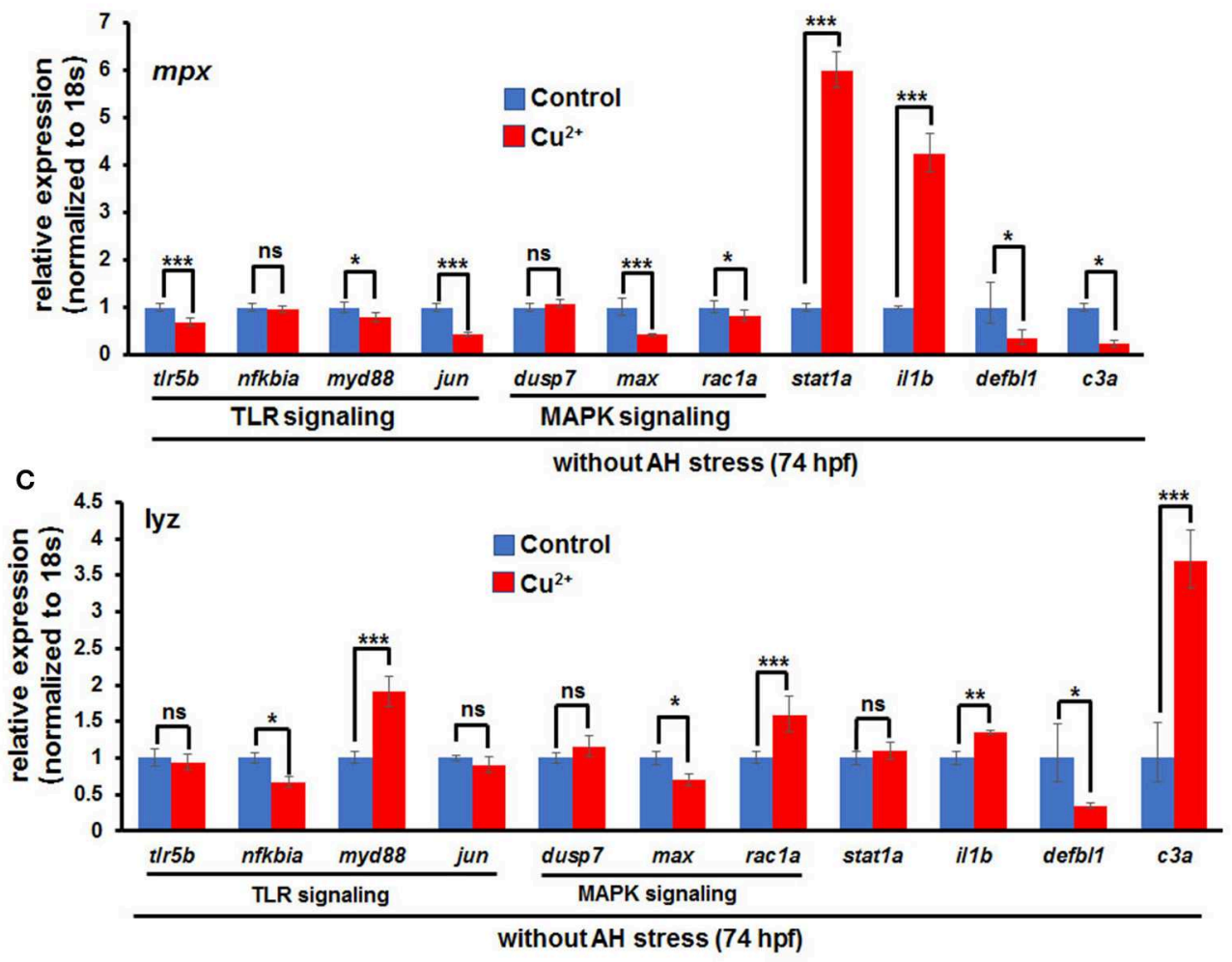

FIGURE 8 | Expression of immune-related genes in copper-stressed macrophages and neutrophils under no A. hydrophila infection conditions. Expression of immune-related genes, including TLR signaling genes, MAPK signaling genes, il1b, stat1a, and c3a, in copper-stressed coro1a-GFP-positive cells (A), mpx-GFP-positive cells (B), and lyz-GFP-positive cells (C). Three biological replicates were performed. ANOVA post-hoc Tukey's test. Data are presented as mean \pm SD. ${ }^{\star \star \star} P<0.001 ;{ }^{\star \star} P<0.01 ;{ }^{\star} P<0.05$; and ns, no significance.

the copper-induced culture condition degradation with $A$. hydrophila-induced increased mortality in fish larvae, but also demonstrated that the ROS-mediated apoptosis, the downregulated phagocytic activities, and the non-sustainable immune responses occurred in macrophages and neutrophils together contributed to the sensitivity of copper-stressed fish larvae to $A$. hydrophila infection.

A. hydrophila was revealed to increase the expression of immune genes and induce mortality in zebrafish larvae, suggesting that $A$. hydrophila used in this study is a pathogenic bacterium for zebrafish larvae. A significant increase of mortality was observed in copper-stressed larvae even at $A$. hydrophila concentration of $10^{6} \mathrm{cfu} / \mathrm{ml}$, and the mortality increased with the increasing infection concentration of $A$. hydrophila. Additionally, compared with injury, copper stress might be a more important contributor to A. hydrophila-induced mortality in zebrafish larvae. The integrated observations in this study indicate that metal copper, similar to other environmental factors or stressors, such as hypoxia stress (32), specific psychological stressors $(33,34)$, etc., could induce 


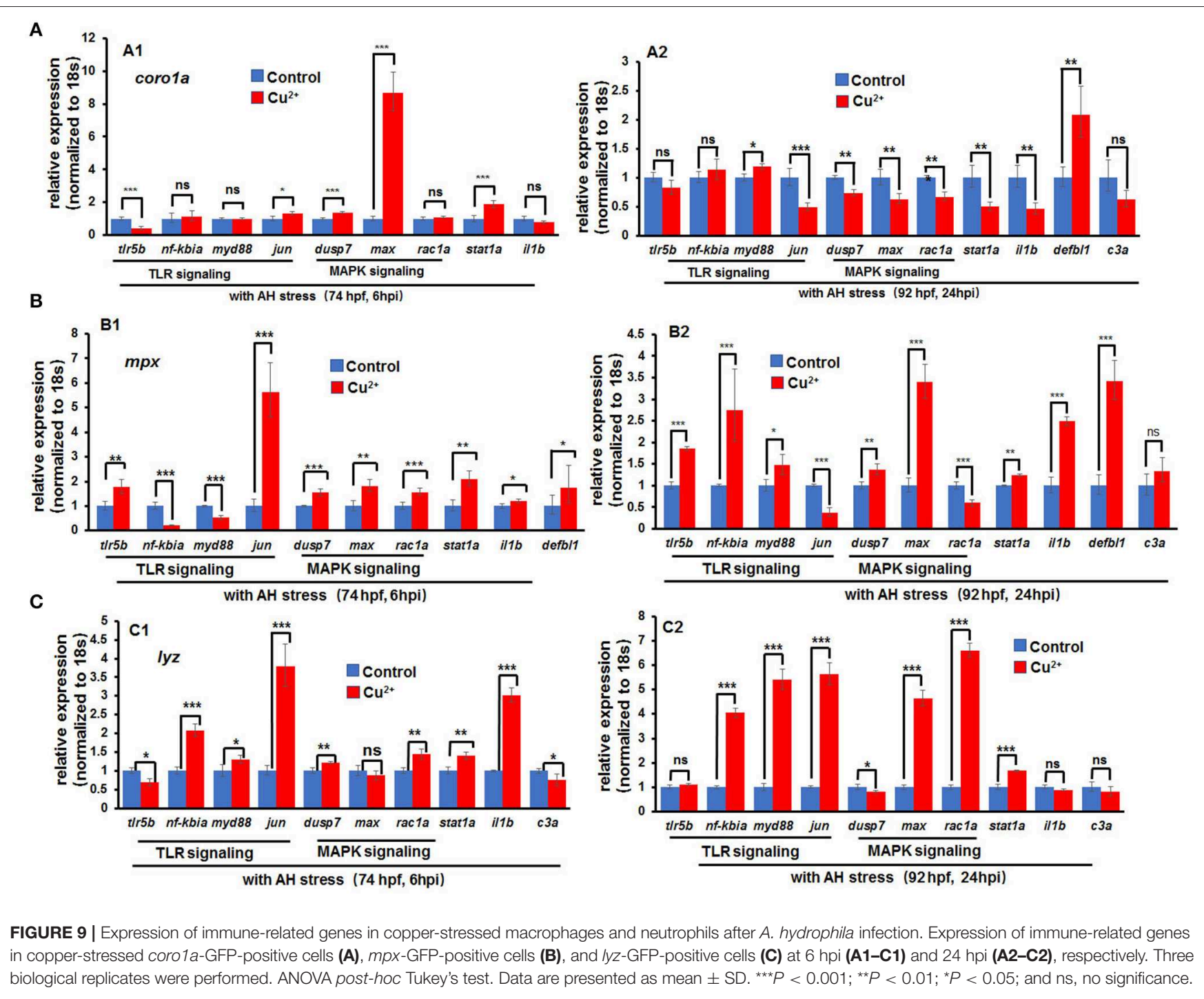

a significant increase in the susceptibility of vertebrates to pathogenic infection.

It was revealed that neutrophils and macrophages in copper-stressed embryos responded very quickly to $A$. hydrophila infection in this study, suggesting that copper might promote the responses of neutrophil and macrophage cells to bacteria-infected locus. mROS has been reported to link with macrophage-mediated bactericidal activity (35-37) and regulate neutrophil directional migration (25). In this study, the oxidative phosphorylation (OXPHOS) and ROS levels were observed to be up-regulated in neutrophil and macrophage cells in copper-stressed embryos, suggesting that high levels of oxidation stress might augment the rapid responses of the cells to the infected locus. Additionally, in this study, immune genes such as $i l-6$ and $i l-1 \beta$ exhibited significantly increased expression in copper-stressed neutrophils and macrophages, which might also contribute to the rapid responses of the cells to A. hydrophila infection in copper-stressed zebrafish larvae. The points raised here are consistent with the report showing that ROS and $i l-1 \beta$ act together in regulating neutrophil migration (25).

Additionally, the recruited differences of GFP-positive cells between corola and $m p x$ and $l y z$ lines indicate that neutrophils and macrophages might respond to A. hydrophila infection in different time windows, and neutrophils might be recruited to infected locus first, followed by macrophages in the corola transgenic line. These observations here are consistent with recent studies reporting that neutrophils are the first phagocytes to arrive at the inflammation locus as the major scavenger while macrophages emerge later to remove the cell debris and apoptotic cells $(7,38,39)$.

However, phagocytic activities were significantly downregulated in copper-stressed neutrophil and macrophage cells, as indicated by the significant reduction in both the percentage of red E. coli bioparticle positive cells in the total corola- or $l y z$-GFP-positive cells and the number of red $E$. coli bioparticles in each neutrophil or macrophage in copper-stressed larvae, 
despite increased expression of lysosome and phagosome genes observed in those cells. Neutrophils were the primary cells scavenging apoptotic bodies and small cell debris, in spite of their limited phagocytic capacity and rapid apoptosis (40). An activated macrophage could engulf more pieces of large cell debris, including apoptotic neutrophils (7). Thus, it could be deduced that the copper-stressed neutrophil and macrophage cells with reduced phagocytic activities could be recruited very quickly to the A. hydrophila-infected sites, but they could not effectively phagocyte the bacteria and remove the dead cells and cell debris, which might be a potential molecular mechanism underlying the copper-induced increased susceptibility to $A$. hydrophila infection for zebrafish larvae. However, it still remains unknown whether copper destroys the lysosome function in neutrophil and macrophage cells.

The percentage of apoptosis in neutrophils and macrophages showed a significant increase from around 5\% in the control larvae to over $70 \%$ in copper-stressed larvae, in contrast to a slight increase in non-GFP-positive cells in copper-stressed larvae. These data suggest that copper might specifically induce high level of apoptosis in neutrophil and macrophage cells, which might be another contributor to the increased susceptibility of copper-stressed larvae to A. hydrophila infection. Copperstressed neutrophil and macrophage cells showed that an increase in ROS and the mROS has been revealed to initiate apoptosis via caspase 8 or caspase2, and then trigger up-regulated expression of bid, bcl2, bax bad, bim, caspase9, etc $(41,42)$. Up-regulated expression was observed in caspase 8 and caspase 9 and annexin V-positive but PI-negative neutrophil and macrophage cells in copper-stressed neutrophil and macrophage cells, suggesting that the cells are apoptotic rather than necroptotic or pyroptotic. Moreover, the copper-stressed neutrophil and macrophage cells showed an increase in the expression of caspase2, caspase8, bid, bax, and bad, as well as their downstream caspase9, caspase3, caspase6, and caspase7, but a decrease in the expression of noxa. This implies that it is DNA damage or ROS that stimulates mitochondrion-linked apoptosis in copper-stressed embryos, which is consistent with a recent report summarizing the different cellular psychological stressors in stimulating apoptosis (42). Given the significantly increased mROS-mediated apoptosis specifically occurring in neutrophil and macrophage cells rather than non-neutrophil and macrophage cells, we demonstrated that copper-induced mROS might function more strikingly in innate immune cells in apoptosis compared with that in other cells, consisting with a point that mitochondria in neutrophils act a role restricted to apoptosis (43).

Furthermore, mROS has been reported to augment macrophage bactericidal activities (35-37), while in this study, with increased susceptibility to A. hydrophila infection, the copper-stressed neutrophils and macrophages showed an increase in ROS level, but a reduction in bactericidal activity. This implicates that copper might induce an extremely high level of ROS, leading to apoptosis. Additionally, the apoptosis in neutrophil and macrophage cells might destroy their phagocytic activities in copper-stressed larvae.

In this study, RNA-Seq (44) and cell direct qRT-PCR $(30,31)$ analyses revealed that the immune genes, such as proinflammatory cytokines, MAPK signaling genes, and TLR signaling genes, exhibited significantly increased expression in copper-stressed corola, $m p x$, and lyz, especially in corolapositive cells. It has been reported that ROS-induced signaling can provoke the synthesis of proinflammatory cytokines $(45,46)$, trigger MAPK signaling activity (47), and regulate the expression and localization of TLRs $(48,49)$. Thus, we speculate that the increased expression of the immune genes in the macrophages and neutrophils might respond to the elevated ROS occurred in the cells in this study.

However, after $A$. hydrophila infection, immune-related genes, such as $i l-1 \beta$, stat 1 , and MAPK signaling genes, including $d u s p 7$, max, and rac1a, could maintain up-regulated expression at $6 \mathrm{hpi}$, but exhibited significantly reduced expression at 24 hpi in corola-positive neutrophil and macrophage cells. These observations not only suggest that those neutrophil and macrophage cells in copper-stressed embryos were subject to excessive inflammation/infection and unable to resolve inflammation in a timely fashion, but also further convince that the activation of immune genes in copper-stressed macrophages and neutrophils resulted in elevated ROS rather than pathogen infection. It is well-known that ROS-induced MAPK and TLR/MyD88 signaling will lead to the activation of caspase 8 and caspase 3 , resulting in apoptosis in cells $(47,50)$. Thus, the ROS/MAPK and TLR/caspase-induced apoptosis might contribute to the inability of immune cells to respond effectively and sustainably to a subsequent bacterial challenge in copperstressed larvae, which might further contribute to the increased susceptibility of copper-stressed larvae to A. hydrophila infection.

\section{DATA AVAILABILITY STATEMENT}

The datasets generated for this study are available on request to the corresponding author.

\section{ETHICS STATEMENT}

All animals and experiments were conducted in accordance with the Guidelines for Experimental Animals approved by the Institutional Animal Care and Use Ethics Committee of Huazhong Agricultural University (permit number HZAUFI2016-007).

\section{AUTHOR'S NOTE}

In this article, for the first time, we unveiled the transcriptional profiles of innate immune macrophage and neutrophil cells in fish larvae under environmental polluter copper stresses via RNA-Seq assays and linked the susceptibility of copperstressed larvae to inflammatory stimuli with the reduced phagocytic activities and non-sustainable immune responses of the aforementioned cells. Mechanistically, we found that copper specifically induced macrophage and neutrophil apoptosis in the stressed larvae via inducing ROS and triggering mROS mediating apoptosis signaling in the cells. Briefly, in this study, we firstly demonstrated the potential molecular mechanisms 
underlying opportunistic pathogen in producing mortalities and diseases in fish under environmental polluter copper stresses and provided some inspiration to intensively study fish embryonic immune responses to opportunistic pathogens under stresses.

\section{AUTHOR CONTRIBUTIONS}

MC, JX, and J-XL designed the experiments and wrote the manuscript. YL provided the pathogen $\mathrm{AH}$ and helped to design the experiments. YL and $\mathrm{M}-\mathrm{XC}$ helped in preparing the manuscript.

\section{FUNDING}

This work was supported by the National Key R\&D Program of China (2018YFD0900101), by the project 2662018JC024 of the

\section{REFERENCES}

1. Gray C, Loynes CA, Whyte MKB, Crossman DC, Renshaw SA, Chico TJA. Simultaneous intravital imaging of macrophage and neutrophil behaviour during inflammation using a novel transgenic zebrafish. Thromb Haemost. (2011) 105:811-9. doi: 10.1160/TH10-08-0525

2. Le GD, Redd MJ, Colucci-Guyon E, Murayama E, Kissa K, Briolat V, et al. Origins and unconventional behavior of neutrophils in developing zebrafish. Blood. (2008) 111:132-41. doi: 10.1182/blood-2007-06-095398

3. Garg N, Popov VL, Papaconstantinou J. Profiling gene transcription reveals a deficiency of mitochondrial oxidative phosphorylation in Trypanosoma cruzi-infected murine hearts: implications in chagasic myocarditis development. Biochim Biophys Acta. (2003) 1638:106-20. doi: 10.1016/S0925-4439(03)00060-7

4. Herbomel P, Thisse B, Thisse C. Ontogeny and behaviour of early macrophages in the zebrafish embryo. Development. (1999) 126:3735-45.

5. Kanther M, Rawls JF. Host-microbe interactions in the developing zebrafish. Curr Opin Immunol. (2010) 22:10-19. doi: 10.1016/j.coi.2010.01.006

6. Ellett F, Pase L, Hayman JW, Andrianopoulos A, Lieschke GJ. mpeg1 promoter transgenes direct macrophage-lineage expression in zebrafish. Blood. (2011) 117:e49-56. doi: 10.1182/blood-2010-10-314120

7. Li L, Yan B, Shi YQ, Zhang WQ, Wen ZL. Live imaging reveals differing roles of macrophages and neutrophils during zebrafish tail fin regeneration. J Biol Chem. (2012) 287:25353-60. doi: 10.1074/jbc.M112.349126

8. Meijer AH, van der Vaart M, Spaink HP. Real-time imaging and genetic dissection of host-microbe interactions in zebrafish. Cell Microbiol. (2014) 16:39-49. doi: 10.1111/cmi.12236

9. Tran NT, Gao ZX, Zhao HH, Yi SK, Chen BX, Zhao YH, et al. Transcriptome analysis and microsatellite discovery in the blunt snout bream (Megalobrama amblycephala) after challenge with Aeromonas hydrophila. Fish Shellfish Immunol. (2015) 45:72-82. doi: 10.1016/j.fsi.2015.01.034

10. Mu YN, Ding F, Cui P, Ao JQ, Hu SN, Chen XH. Transcriptome and expression profiling analysis revealed changes of multiple signaling pathways involved in immunity in the large yellow croaker during Aeromonas hydrophila infection. BMC Genomics. (2010) 11:506. doi: 10.1186/1471-2164-11-506

11. Cao H, Yang Y, Lu L, Yang X, Ai X. Effect of copper sulfate on Bdellovibrio growth and bacteriolytic activity towards gibel carp-pathogenic Aeromonas hydrophila. Can J Microbiol. (2018) 64:1054-8. doi: 10.1139/cjm-2018-0165

12. Johnson A, Carew E, Sloman KA. The effects of copper on the morphological and functional development of zebrafish embryos. Aquat Toxicol. (2007) 84:431-8. doi: 10.1016/j.aquatox.2007.07.003

13. Tilton FA, Bammler TK, Gallagher EP. Swimming impairment and acetylcholinesterase inhibition in zebrafish exposed to copper or chlorpyrifos
Fundamental Research Funds for the Central University (to J$\mathrm{XL}$ ), and by the project of Key Laboratory of Biodiversity and Conservation of Aquatic Organisms. The funders had no role in study design, data collection and analysis, decision to publish, or preparation of the manuscript.

\section{ACKNOWLEDGMENTS}

We would like to thank Professor Li Li (Southwest University, China) for providing the three kinds of transgenic zebrafish lines [Tg(corola:eGFP), $\operatorname{Tg}($ lyz:eGFP), and $\operatorname{Tg}(m p x: e G F P)]$.

\section{SUPPLEMENTARY MATERIAL}

The Supplementary Material for this article can be found online at: https://www.frontiersin.org/articles/10.3389/fimmu. 2019.02599/full\#supplementary-material

separately, or as mixtures. Comp Biochem Physiol C. (2011) 153:916. doi: $10.1016 /$ j.cbpc.2010.07.008

14. Zhang T, Xu L, Wu JJ, Wang WM, Mei J, Ma XF, et al. Transcriptional responses and mechanisms of copper-induced dysfunctional locomotor behavior in zebrafish embryos. Toxicol Sci. (2015) 148:299-310. doi: 10.1093/toxsci/kfv184

15. Kondera E, Witeska M. Cadmium and copper reduce hematopoietic potential in common carp (Cyprinus carpio L.) head kidney. Fish Physiol Biochem. (2013) 39:755-64. doi: 10.1007/s10695-012-9738-6

16. Cengiz D, Halit D, Ramazan E, Abidin S, Murat A, Murat A. Altered serum levels of elements in acute leukemia cases in Turkey. Asian Pac J Cancer Prev. (2011) 12:3471-4.

17. Hall C, Flores MV, Storm T, Crosier K, Crosier P. The zebrafish lysozyme C promoter drives myeloid-specific expression in transgenic fish. BMC Dev Biol. (2007) 7:42. doi: 10.1186/1471-213X-7-42

18. Renshaw SA, Loynes CA, Trushell DMI, Elworthy S, Ingham PW, Whyte MKB. A transgenic zebrafish model of neutrophilic inflammation. Blood. (2006) 108:3976-8. doi: 10.1182/blood-2006-05-024075

19. Kimmel CB, Ballard WW, Kimmel SR, Ullmann B, Schilling TF. Stages of embryonic development of the zebrafish. Dev Dyn. (1995) 203:253310. doi: 10.1002/aja.1002030302

20. Olivari FA, Hernandez PP, Allende ML. Acute copper exposure induces oxidative stress and cell death in lateral line hair cells of zebrafish larvae. Brain Res. (2008) 1244:1-12. doi: 10.1016/j.brainres.2008.09.050

21. Li JJ, Tang Q, Li Y, Hu BR, Ming ZY, Fu Q, et al. Role of oxidative stress in the apoptosis of hepatocellular carcinoma induced by combination of arsenic trioxide and ascorbic acid. Acta Pharmacol Sin. (2010) 27:107884. doi: 10.1111/j.1745-7254.2006.00345.x

22. Cui B, Ren L, Xu QH, Yin LY, Zhou XY, Liu JX. Silver_ nanoparticles inhibited erythrogenesis during zebrafish embryogenesis. Aquat Toxicol. (2016) 177:295-305. doi: 10.1016/j.aquatox.2016.06.005

23. Xu L, Xu QH, Zhou XY, Yin LY, Guan PP, Zhang T, et al. Mechanisms of silver_nanoparticles induced hypopigmentation in embryonic zebrafish. Aquat Toxicol. (2017) 184:49-60. doi: 10.1016/j.aquatox.2017. 01.002

24. Zhang YJ, Wang ZY, Zhaoa G, Liu JX. Silver nanoparticles affect lens rather than retina development in zebrafish embryos. Ecotoxicol Environ Safety. (2018) 163:279-88. doi: 10.1016/j.ecoenv.2018.07.079

25. Yan B, Han P, Pan L, Lu W, Xiong J, Zhang M, et al. IL-1beta and reactive oxygen species differentially regulate neutrophil directional migration and Basal random motility in a zebrafish injury-induced inflammation model. $J$ Immunol. (2014) 192:5998-6008. doi: 10.4049/jimmunol.1301645

26. Zhu L, Zheng JS, Wang WM, Luo Y. Complete genome sequence of highly virulent Aeromonas hydrophila strain D4, isolated from a diseased 
blunt-snout bream in China. Microbiol Resour Announc. (2019) 8:e103518. doi: 10.1128/MRA.01035-18

27. Saraceni PR, Romero A, Figueras A, Novoa B. Establishment of infection models in zebrafish larvae (Danio rerio) to study the pathogenesis of Aeromonas hydrophila. Front Microbiol. (2016) 7:1219. doi: $10.3389 /$ fmicb.2016.01219

28. Manoli M, Driever W. Fluorescence-activated cell sorting (FACS) of fluorescently tagged cells from zebrafish larvae for RNA isolation. Cold Spring Harb Protoc. (2012) 2012:879-86. doi: 10.1101/pdb.prot069633

29. Gallardo VE, Behra M. Fluorescent activated cell sorting (FACS) combined with gene expression microarrays for transcription enrichment profiling of zebrafish lateral line cells. Methods. (2013) 62:226-31. doi: 10.1016/j.ymeth.2013.06.005

30. Guo G, Luc S, Marco E, Lin TW, Peng C, Kerenyi M, et al. Mapping cellular hierarchy by single-cell analysis of the cell surface repertoire. Cell Stem Cell. (2013) 13:492-505. doi: 10.1016/j.stem.2013.07.017

31. Liu JX, Xu QH, Li S, Yu XD, Liu WY, Ouyang G, et al. Transcriptional factors Eaf1/2 inhibit endoderm and mesoderm formation via suppressing TGF- $\beta$ signaling. Biochim Biophys Acta. (2017) 1860:S1874939917300482. doi: 10.1016/j.bbagrm.2017.09.001

32. Yuan Z, Liu S, Yao J, Zeng Q, Tan S, Liu Z. Expression of Bcl-2 genes in channel catfish after bacterial infection and hypoxia stress. Dev Comp Immunol. (2016) 65:79-90. doi: 10.1016/j.dci.2016.06.018

33. Sheridan JF, Stark JL, Avitsur R, Padgett DA. Social disruption, immunity, and susceptibility to viral infection. Role of glucocorticoid insensitivity and NGF. Ann N $\quad Y$ Acad Sci. (2000) 917:894905. doi: 10.1111/j.1749-6632.2000.tb05455.x

34. Hodgson PD, Aich P, Stookey J, Popowych Y, Potter A, Babiuk L, et al. Stress significantly increases mortality following a secondary bacterial respiratory infection. Vet Res. (2012) 43:21. doi: 10.1186/1297-9716-43-21

35. Hall CJ, Boyle RH, Astin JW, Flores MV, Oehlers SH, Sanderson LE, et al. Immunoresponsive gene 1 augments bactericidal activity of macrophagelineage cells by regulating beta-oxidation-dependent mitochondrial ROS production. Cell Metab. (2013) 18:265-78. doi: 10.1016/j.cmet.2013.06.018

36. Roca FJ, Ramakrishnan L. TNF dually mediates resistance and susceptibility to mycobacteria via mitochondrial reactive oxygen species. Cell. (2013) 153:52134. doi: 10.1016/j.cell.2013.03.022

37. West AP, Brodsky IE, Rahner C, Woo DK, Erdjument-Bromage H, Tempst $\mathrm{P}$, et al. TLR signalling augments macrophage bactericidal activity through mitochondrial ROS. Nature. (2011) 472:476-543. doi: 10.1038/nature09973

38. Martin P, Leibovich SJ. Inflammatory cells during wound repair: the good, the bad and the ugly. Trends Cell Biol. (2005) 15:599-607. doi: 10.1016/j.tcb.2005.09.002

39. Arnold L, Henry A, Poron F, Baba-Amer Y, van Rooijen N, Plonquet A, et al. Inflammatory monocytes recruited after skeletal muscle injury switch into antiinflammatory macrophages to support myogenesis. J Exp Med. (2007) 204:1057-69. doi: 10.1084/jem.20070075

40. Carl N. Neutrophils and immunity: challenges and opportunities. Nat Rev Immunol. (2006) 6:173-82. doi: 10.1038/nri1785
41. Fan TJ, Han LH, Cong RS, Liang J. Caspase family proteases and apoptosis. Acta Biochim Biophys Sin. (2010) 37:71927. doi: 10.1111/j.1745-7270.2005.00108.x

42. Prasad V, Chandele A, Jagtap JC, Sudheer KP, Shastry P. ROStriggered caspase 2 activation and feedback amplification loop in $\beta$-carotene-induced apoptosis. Free Radic Biol Med. (2006) 41:431-42. doi: 10.1016/j.freeradbiomed.2006.03.009

43. Maianski NA, Geissler J, Srinivasula SM, Alnemri ES, Roos D, Kuijpers TW. Functional characterization of mitochondria in neutrophils: a role restricted to apoptosis. Cell Death Different. (2004) 11:143-53. doi: 10.1038/sj.cdd.4401320

44. Tang F, Barbacioru C, Wang Y, Nordman E, Lee C, Xu N, et al. mRNA-Seq whole-transcriptome analysis of a single cell. Nat Methods. (2009) 6:37782. doi: $10.1038 /$ nmeth. 1315

45. Curtsinger JM, Johnson CM, Mescher MF. CD8 T cell clonal expansion and development of effector function require prolonged exposure to antigen, costimulation, and signal 3 cytokine. J Immunol. (2003) 171:516571. doi: 10.4049/jimmunol.171.10.5165

46. Sklavos MM, Tse HM, Piganelli JD. Redox modulation inhibits CD8 T cell effector function. Free Radic Biol Med. (2008) 45:1477-86. doi: 10.1016/j.freeradbiomed.2008.08.023

47. Lan H, Yuan HY, Lin CY. Sulforaphane induces p53-deficient SW480 cell apoptosis via the ROS-MAPK signaling pathway. Mol Med Rep. (2017) 16:7796-804. doi: 10.3892/mmr.2017.7558

48. Seleme MC, Lei WQ, Burg AR, Goh KY, Metz A, Steele C, et al. Dysregulated TLR3-dependent signaling and innate immune activation in superoxide-deficient macrophages from nonobese diabetic mice. Free Radic Biol Med. (2012) 52:2047-56. doi: 10.1016/j.freeradbiomed.2012. 01.027

49. Nakahira K, Kim HP, Geng XH, Nakao A, Wang X, Murase N, et al. Carbon monoxide differentially inhibits TLR signaling pathways by regulating ROSinduced trafficking of TLRs to lipid rafts. J Exp Med. (2006) 203:237789. doi: $10.1084 /$ jem. 20060845

50. Li PM, Li YL, Liu B, Wang WJ, Wang YZ, Li Z. Curcumin inhibits MHCC97H liver cancer cells by activating ROS/TLR-4/caspase signaling pathway. Asian Pac J Cancer Prev. (2014) 15:2329-34. doi: 10.7314/APJCP.2014.15. 5.2329

Conflict of Interest: The authors declare that the research was conducted in the absence of any commercial or financial relationships that could be construed as a potential conflict of interest.

Copyright $\odot 2019$ Chen, Luo, Xu, Chang and Liu. This is an open-access article distributed under the terms of the Creative Commons Attribution License (CC BY). The use, distribution or reproduction in other forums is permitted, provided the original author(s) and the copyright owner(s) are credited and that the original publication in this journal is cited, in accordance with accepted academic practice. No use, distribution or reproduction is permitted which does not comply with these terms. 